\title{
Leishmania, Babesia and Ehrlichia in urban pet dogs: co-infection or cross-reaction in serological methods?
}

\author{
Felipe da Silva Krawczak ${ }^{[1]}$ Ilka Afonso Reis ${ }^{[2]}$, Julia Angélica da Silveira ${ }^{[3]}$, \\ Daniel Moreira Avelar ${ }^{[4]}$, Andréza Pain Marcelino ${ }^{[4]}$, Guilherme Loureiro Werneck ${ }^{[5]}$, \\ Marcelo Bahia Labruna ${ }^{[1]}$ and Gustavo Fontes Paz ${ }^{[6]}$
}

[1]. Faculdade de Medicina Veterinária e Zootecnia, Departamento de Medicina Veterinária Preventiva e Saúde Animal, Universidade de São Paulo, São Paulo, SP. [2]. Departamento de Estatística, Instituto de Ciências Exatas, Universidade Federal de Minas Gerais, Belo Horizonte, MG. [3]. Departamento de Parasitologia, Instituto de Ciências Biológicas, Universidade Federal de Minas Gerais, Belo Horizonte, MG. [4]. Serviço de Doenças Parasitárias, Divisão de Epidemiologia e Controle de Doenças, Fundação Ezequiel Dias, Belo Horizonte, MG. [5]. Departamento de Epidemiologia, Instituto de Medicina Social, Universidade do Estado do Rio de Janeiro, Rio de Janeiro, RJ. [6]. Grupo de Estudos em Leishmanioses, Centro de Pesquisas René Rachou, Fundação Oswaldo Cruz, Belo Horizonte, MG.

\begin{abstract}
Introduction: The present study was designed to assess the occurrence of co-infection or cross-reaction in the serological techniques used for detecting the anti-Leishmania spp., -Babesia canis vogeli and -Ehrlichia canis antibodies in urban dogs from an area endemic to these parasites. Methods: The serum samples from dogs were tested for the Babesia canis vogeli strain Belo Horizonte antigen and Ehrlichia canis strain São Paulo by immunofluorescence antibody test (IFAT) and by antiLeishmania immunoglobulin $\mathrm{G}(\mathrm{IgG})$ antibody detection to assess Leishmania infection. We used the following four commercial kits for canine visceral leishmaniasis: ELISA, IFAT, Dual Path Platform (DPP) (Bio Manguinhos®/FIOCRUZ/MS) and a rK39 RDT (Kalazar Detect Canine Rapid Test; Inbios). Results: Of 96 serum samples submitted to serological assays, 4 (4.2\%) were positive for Leishmania as determined by ELISA; 12 (12.5\%), by IFAT; 14 (14.6\%) by rK39 RDT; and 20 (20.8\%), by DPP. Antibodies against Ehrlichia and Babesia were detected in 23/96 (23.9\%) and 30/96 (31.2\%) samples, respectively. No significant association was identified between the results of tests for detecting Babesia or Ehrlichia and those for detecting Leishmania (p-value>0.05). Conclusions: In the present study, we demonstrated co-infection with Ehrlichia or Babesia and Leishmania in dogs from Minas Gerais (Brazil); we also found that the serological tests that were used did not cross-react.
\end{abstract}

Keywords: Immunochromatographic test. Enzyme-linked immunosorbent assay. Immunofluorescence antibody test. Canine visceral leishmaniasis.

\section{INTRODUCTION}

Vector-borne dog infections such as ehrlichiosis, babesiosis and leishmaniasis are among the most common canine diseases in the tropical, sub-tropical and temperate climate regions of the world. Co-infection with more than one pathogen is common due to the abundance of hematophagous vectors such as ticks and sand flies and due to the ability of arthropod vectors to host and transmit several pathogens simultaneously ${ }^{(1)}$. Ehrlichia canis (Rickettsiales: Anaplasmataceae), an intracellular Gram-negative bacterium that infects monocytes, is the causative agent of canine monocytic ehrlichiosis and is transmitted by the tick Rhipicephalus sanguineus $^{(2)}$. Piroplasms are tick-borne apicomplexan parasites that infect the erythrocytes of domestic and wild animals.

Address to: Dr. Gustavo Fontes Paz. Grupo de Estudos em Leishmanioses/ CPqRR/FIOCRUZ. Av. Augusto de Lima 1715, 30190-002 Belo Horizonte, MG, Brasil.

Phone: 5531 3349-7721; Fax: 5531 3349-7795

e-mail: gustavopaz@cpqrr.fiocruz.br

Received 28 November 2014

Accepted 10 February 2015
Babesia (Piroplasmida: Babesiidae) infections in dogs are caused by at least six genetically distinct species; babesiosis in Brazil is caused predominantly by Babesia canis vogeli ${ }^{(3)}{ }^{(4)}$.

Canine leishmaniasis is a vector-borne disease caused by protozoa of the genus Leishmania (Kinetoplastida: Trypanosomatidae), and the most important etiological agent of canine leishmaniasis is Leishmania infantum (syn. Leishmania chagasi). The control of canine visceral leishmaniasis (CVL) in Brazil is based primarily on eliminating seropositive dogs. Until 2012, CVL had been diagnosed using the immunofluorescent antibody test (IFAT), a method recommended for confirming positive cases detected by enzyme-linked immunosorbent assay (ELISA). Recently, to improve the accuracy of diagnosing CVL, the Brazilian Ministry of Health has recommended the use of an immunochromatographic rapid test consisting of rK26 and rK39 recombinant antigens, the Dual-Path Platform (DPP; Bio-Manguinhos/FIOCRUZ, Rio de Janeiro, Brazil) to screen infected dogs, and ELISA Bio-Manguinhos/FIOCRUZ to confirm the positive results ${ }^{(5)}$.

Some researchers have reported that antibodies against E. canis and B. canis are cross-reactive with Leishmania spp. in the common serological tests that have been applied to detect 
dogs infected by Leishmania spp. ${ }^{(6)(7)(8)}$. The aim of this study was to evaluate the possible relationship between the naturally occurring anti-Leishmania spp.,-Babesia spp. and-Ehrlichia spp. antibodies in Brazilian dogs.

\section{METHODS}

\section{Study area}

This study was conducted in a region to the Northeast of Belo Horizonte (latitude: $19^{\circ} 55^{\prime} 15^{\prime \prime} \mathrm{S}$; longitude: 4356'16" W) that is endemic for canine vector-borne parasitic diseases caused by organisms of the genera Leishmania, Babesia, and Ehrlichia ${ }^{(9)(10)(11) . ~}$ The study area was selected based on environmental and socioeconomical characteristics and consisted of a relatively flat, densely populated urban district containing predominantly oneor two-story buildings with woody vegetation between the plots.

\section{Animals}

The canine population within the study area consisted of 120 domestic dogs that were domiciliated, corresponding to almost every resident dog in the area during the period of our study (according to the local health department); however, only $96(80 \%)$ of these dogs could be surveyed. The remaining dogs could not be evaluated because either the owners refused to participate in the study or the residence was closed at the start of the study.

Blood samples were collected by venipuncture during JulyAugust 2013 and transferred to tubes without anticoagulant. Serum samples were obtained by centrifugation 2,500rpm for 15 minutes and stored at $-70^{\circ} \mathrm{C}$ until use.

To detect the presence of clinical signs of disease, each dog was subjected to one clinical examination that was conducted during the experimental period. Dog owners were interviewed using a semi-structured questionnaire with questions covering the gender, age and breed of each dog.

\section{Serological methods}

Serum samples were tested for the presence of antiLeishmania immunoglobulin $\mathrm{G}$ ( $\mathrm{IgG}$ ) antibodies using the following four commercial canine visceral leishmaniasis kits: enzyme-linked immunosorbent assay (ELISA)
(Bio-Manguinhos ${ }^{\circledR} /$ FIOCRUZ/MS), immunofluorescence antibody test (IFAT) (Bio-manguinhos $® / F I O C R U Z / M S)$, Dual Path Platform (DPP) (Bio-manguinhos ${ }^{\circledR} /$ FIOCRUZ/MS), and rK39 RDT (Kalazar Detect Canine Rapid Test; Inbios). Dogs were considered positive for Leishmania infection if found to be reactive by IFAT, DPP, ELISA or rK39 RDT. To detect anti-Ehrlichia canis antibodies, sera were tested by IFAT in house using E. canis strain São Paulo antigen ${ }^{(12)}$ with a cut-off titer of $1: 80^{(13)(14)}$. To detect anti- $B$. canis vogeli antibodies, sera were tested by IFAT in house using $B$. canis vogeli strain Belo Horizonte antigen ${ }^{(15)}$ with a cut-off titer of $1: 40^{(16)}$.

\section{Statistical analysis}

Fisher's exact test was used for statistical analysis ( $p$-value $<0.05$ ) to evaluate the possible association between the results of tests for detecting Babesia or Ehrlichia infection with those for detecting Leishmania infection.

This study was submitted to and approved by the Ethics Committee for Research with Animals of the Oswaldo Cruz Foundation [(Comissão de Ética no Uso de Animais/Fundação Oswaldo Cruz (CEUA/FIOCRUZ)] under protocol number LW-76/12. All procedures involving experimental animals were conducted according to the guidelines of the Brazilian College for Experiments with Animals [Colégio Brasileiro de Experimentação Animal (COBEA)].

\section{RESULTS}

The studied dog population consisted of 42 (43.7\%) males and $54(56.3 \%)$ females, and the average age was $5.8 \pm 1.1$ years (range: 3 months to 17 years). The breeds included in the population were mongrels $(53.1 \%)$, poodles $(24 \%)$, Doberman pinschers $(8.3 \%)$, Yorkshire terriers $(3.1 \%)$, boxers, cocker spaniels, Labradors and German shepherds (8.4\%) and others (3.1\%).

Clinical examination conducted at the time of blood sample collection revealed that all dogs were apparently healthy and did not show any visible signs of disease.

Tables 1, 2 and 3 summarize the results of the different diagnostic tests used in this comparative study. Of the 96 serum samples submitted to serological assays, 4 (4.2\%) were considered positive for Leishmania by ELISA; 12 (12.5\%), by IFAT; 14 (14.6\%), by rK39 RDT; and 20 (20.8\%), by DPP.

TABLE 1 - Frequency of infection and co-infection by Ehrlichia canis and Leishmania spp. according to IFAT, ELISA, DPP and rK39 RDT.

\begin{tabular}{|c|c|c|c|c|c|c|c|c|}
\hline \multirow[b]{3}{*}{ Ehrlichia canis } & \multicolumn{8}{|c|}{ Leishmania spp. (positive results) } \\
\hline & \multicolumn{2}{|c|}{ IFAT } & \multicolumn{2}{|c|}{ ELISA } & \multicolumn{2}{|c|}{ DPP } & \multicolumn{2}{|c|}{ rK39 RDT } \\
\hline & $\mathrm{n}$ & $\%$ & $\mathrm{n}$ & $\%$ & $\mathrm{n}$ & $\%$ & $\mathrm{n}$ & $\%$ \\
\hline Negative $(n=73)$ & 11 & 15.1 & 3 & 4.1 & 17 & 23.3 & 7 & 9.6 \\
\hline Positive $(n=23)$ & 1 & 4.3 & 1 & 4.3 & 3 & 13.0 & 1 & 4.3 \\
\hline
\end{tabular}

IFAT: immunofluorescence antibody test; ELISA: enzyme-linked immunosorbent assay; DPP: Dual Path Platform; rK39 RDT: Kalazar Detect Canine Rapid Test; Inbios. Fisher's exact test for association: IFI ( $p$-value=0.2826), ELISA ( $p$-value=1.000); DPP (p-value=0.3851), and Kalazar ( $p$-value=0.6752). 
TABLE 2 - Frequency of infection and co-infection by Babesia canis vogeli and Leishmania spp. according to IFAT, ELISA, DPP and rK39 RDT.

\begin{tabular}{|c|c|c|c|c|c|c|c|c|}
\hline \multirow[b]{3}{*}{ Babesia canis vogeli } & \multicolumn{8}{|c|}{ Leishmania spp. (positive results) } \\
\hline & \multicolumn{2}{|c|}{ IFAT } & \multicolumn{2}{|c|}{ ELISA } & \multicolumn{2}{|c|}{ DPP } & \multicolumn{2}{|c|}{ rK39 RDT } \\
\hline & $\mathrm{n}$ & $\%$ & $\mathrm{n}$ & $\%$ & $\mathrm{n}$ & $\%$ & $\mathrm{n}$ & $\%$ \\
\hline Positive $(n=30)$ & 5 & 16.7 & 2 & 6.7 & 8 & 26.7 & 4 & 13.3 \\
\hline Total $(\mathrm{n}=96)$ & 12 & 12.5 & 4 & 4.2 & 20 & 20.8 & 8 & 8.3 \\
\hline
\end{tabular}

IFAT: immunofluorescence antibody test; ELISA: enzyme-linked immunosorbent assay; DPP: Dual Path Platform; rK39 RDT: Kalazar Detect Canine Rapid Test; Inbios. Fisher's exact test for association: IFAT ( $p$-value=0.5075), ELISA (p-value=0.5867), DPP (p-value=0.4179), and Kalazar (p-value=0.2521).

TABLE 3 - Frequency of infection and co-infection by Ehrlichia canis and Babesia canis vogeli according to IFAT.

\begin{tabular}{|c|c|c|c|c|c|c|c|}
\hline \multirow{2}{*}{ Ehrlichia canis } & & \multicolumn{4}{|c|}{ Babesia canis } & & \\
\hline & Negative & 52 & 71.2 & 21 & 28.8 & 73 & 76.0 \\
\hline & Positive & 14 & 60.9 & 9 & 39.1 & 23 & 24.0 \\
\hline & Total & 66 & 68.8 & 30 & 31.2 & 96 & 100.0 \\
\hline
\end{tabular}

IFAT: immunofluorescence antibody test. Fisher's exact test for association: $p$-value $=0.4399$.

For the ELISA+IFAT, ELISA+DPP, and IFAT+DPP combinations, the percentages of positive sera were $4.2 \%$, $4.2 \%$ and $9.5 \%$, respectively.

For the anti-Ehrlichia canis and anti-Babesia canis vogeli antibodies, 23/96 (23.9\%) and 30/96 (31.2\%) samples had detectable antibodies against these agents, respectively.

Simultaneous reactivity to Ehrlichia canis and to Babesia canis vogeli was observed in nine dogs (by IFAT). Simultaneous reactivity to $E$. canis and Leishmania, considering each of the four Leishmania serological tests, was observed in $4.3 \%$ (by IFAT), $4.3 \%$ (by ELISA), 13\% (by DPP), and 4.3\% (by rK39 RDT) of the dogs. Additionally, simultaneous reactivity to B. canis vogeli and Leishmania was found in $16.7 \%$ (IFAT), $6.7 \%$ (ELISA), 26.7\% (DPP), and 13.3\% (rK39 RDT) of the dogs. No significant association was identified between the results of the tests for detecting Babesia and Ehrlichia and those for detecting Leishmania (p-value $>0.05$ ).

\section{DISCUSSION}

In endemic areas, serological tests, which are helpful tools in epidemiological studies, are useful for identifying asymptomatic carrier dogs and for diagnosing chronic infections. Canine monocytotropic ehrlichiosis and canine babesiosis are multisystemic diseases manifesting in acute, subclinical or chronic forms ${ }^{(3)(17)}$. Canine leishmaniasis is a disease in which infection does not always result in clinical illness due to the high prevalence of subclinical infection ${ }^{(18)}$. In the present study, all 96 dogs were diagnosed as asymptomatic according to one clinical examination of each dog, which was conducted during the experimental period. However, this classification has limited value because it does not consider clinicopathological abnormalities and disregards dogs that have widespread organ dysfunction without apparent visual manifestations ${ }^{(19)}$.

The requirements of a serological test for canine leishmaniasis may vary. To confirm clinically suspected cases, the test specificity is the most important feature, whereas a high sensitivity is the most essential feature for surveillance programs or for tests of dogs imported from endemic areas, facilitating the detection of asymptomatic carriers. In our study, all four commercial canine visceral leishmaniasis kits had both high sensitivities and specificities. However, these kits detected considerably fewer asymptomatic cases and varied significantly with respect to their sensitivity and specificity for the different antigens $^{(20)(21)}$.

Immunofluorescent antibody test, enzyme-linked immunosorbent assay and immunochromatographic devices are the most commonly used techniques for detecting antileishmanial antibodies. False positive results due to serological cross-reactivity with other pathogens have been described in all of the above-mentioned serological techniques, particularly for Trypanosoma cruzi infection in North, Central and South America or for other species of Leishmania and tests using whole-parasite crude antigens. Cross-reactions are less likely to occur when using recombinant peptides such as rA2, rK9, rK26 and rK39(22). 
Veterinarians are the key professionals at the companion animal-human interface. Not only do veterinarians provide traditional medical and surgical services for pets, their training in the disciplines of parasitology, microbiology, epidemiology, and public health place them in a unique position to provide advice about matters pertaining to vector-borne diseases.

Researchers and veterinarians have often inferred the existence of cross-reaction in serological assays for detecting canine leishmaniasis in dogs co-infected with E. canis or $B$. canis vogeli. In fact, Mancianti et al. ${ }^{(6)}$ demonstrated crossreactivity of $B$. canis vogeli with anti-Leishmania antibodies using dot-ELISA. Furthermore, Gomes and Cordeiro ${ }^{(23)}$ also observed cross-reaction with Leishmania during serological diagnostic assessments of the disease in dogs with acute phases of $E$. canis or B. canis vogeli infections. These authors suggested that primary treatment of infection with these two pathogens in dogs will be crucial to reverse cross-reaction activity with leishmaniasis. However, notably, dogs may remain seropositive for long periods even after chemosterilization ${ }^{(24)(25)}$.

Co-infection of canine piroplasms with other tick-borne pathogens, such as Ehrlichia canis, Hepatozoon canis, and sand fly-borne Leishmania infantum, is frequent in areas where exposure to ectoparasites is extensive ${ }^{(26)}$. A recent study tested the sera samples from endemic and non-endemic areas of Brazilian leishmaniasis using IFAT and ELISA, as well as IFAT for Ehrlichia and Babesia detection; the authors reported that the serological reactivity to Leishmania and Ehrlichia or Babesia was from co-infection rather than form crossreaction between the agents ${ }^{(27)}$. In our study, these findings are statistically supported because we found evidence of a lack of association between the serological results for detecting antiEhrlichia,-Babesia and-Leishmania antibodies, suggesting that co-infection is more plausible than cross-reaction.

This situation could be explained if we consider the taxonomic classification of these pathogens. The microorganisms of the Ehrlichia genus are intracellular bacteria( ${ }^{(28)}$, and Babesia and Leishmania are two protozoan agents that are phylogenetically different, belonging to the Piroplasmida and Kinetoplastida orders, respectively, indicating that differences in their biology exist ${ }^{(29)}\left({ }^{(30)}\right.$. This phylogenetic distance between these three pathogenic agents could explain the lack of cross-reactions. Nonetheless, cross-reaction activity between nearly related protozoa species has been observed. For example, Zanette et al. ${ }^{(31)}$ used several serological techniques (IFAT, ELISA and rK39 RDT) for detecting Trypanosoma cruzi and Leishmania infantum chagasi, two protozoa species belonging to the Trypanosomatidae family, and observed cross-reaction between these species. In the same study, supporting our results, no cross-reaction was observed between Babesia and Leishmania when using IFAT as a diagnostic test. In contrast to our results, these authors observed cross-reaction between Leishmania and E. canis with ELISAs. Moreover, these authors suggest that Neospora caninum and Toxoplasma gondii were also responsible for the cross-reaction with CVL. However, these findings remain controversial because other studies have demonstrated the absence of cross-reaction between Leishmania and T. gondii ${ }^{(7)}$, E. canis and B. canis $^{(27)}$.
In conclusion, our study suggests the occurrence of a haphazard co-infection pattern in the endemic studied area, and our results do not support serological cross-reaction between Leishmania spp., E. canis and B. canis vogeli.

\section{ACKNOWLEDGMENTS}

The authors wish to thank Dr. Múcio Flávio Barbosa Ribeiro for assistance with the laboratory work.

\section{CONFLICT OF INTEREST}

The authors declare that there is no conflict of interest.

\section{FINANCIAL SUPPORT}

Fundação de Amparo à Pesquisa do Estado de Minas Gerais (FAPEMIG), Fundação de Amparo à Pesquisa do Estado de São Paulo (FAPESP), Programa de Excelência em PesquisaPROEP, Centro de Pesquisas René Rachou (CPqRR), Conselho Nacional de Desenvolvimento Científico e Tecnológico (CNPq) Grant. number 401975/2012-6 and Programa de Apoio à Pesquisa (PAPES VI) da Fundação Oswaldo Cruz (FIOCRUZ) Grant. number 407529/2012-8.

\section{REFERENCES}

1. Yisaschar-Mekuzas Y, Jaffe CL, Pastor J, Cardoso L, Baneth G. Identification of Babesia species infecting dogs using reverse line blot hybridization for six canine piroplasms, and evaluation of co-infection by other vector-borne pathogens. Vet Parasitol 2013; 191:367-373.

2. Stich RW, Schaefer JJ, Bremer WG, Needham GR, Jittapalapong S. Host surveys, ixodid tick biology and transmission scenarios as related to the tick-borne pathogen. Ehrlichia canis. Vet Parasitol 2008; 158:256-273.

3. Dantas-Torres F. Causative agents of canine babesiosis in Brazil. Prev Vet Med 2008a; 83:210-211.

4. Costa Jr LM, Zahler-Rinder M, Ribeiro MF, Rembeck K, Rabelo EM, Pfister K, Passos LM. Use of a Real Time PCR for detecting subspecies of Babesia canis. Vet Parasitol 2012; 188:160-163.

5. Coura-Vital W, Ker HG, Roatt BM, Aguiar-Soares RDO, Leal GGA, Moreira ND, et al. Evaluation of Change in Canine Diagnosis Protocol Adopted by the Visceral Leishmaniasis Control Program in Brazil and a New Proposal for Diagnosis. PLoS ONE 2014; 9: e91009.

6. Mancianti F, Pedonese F, Poli A. Evaluation of dot enzyme-linked immunosorbent assay (dot-ELISA) for the serodiagnosis of canine leishmaniosis as compared with indirect immunofluorescence assay. Vet Parasitol 1996; 65:1-9.

7. Ferreira EC, Lana M, Carneiro M, Reis AB, Paes DV, Da Silva ES, et al. Comparison of serological assays for the diagnosis of canine visceral leishmaniasis in animals presenting different clinical manifestations. Vet Parasitol 2007; 146:235-241.

8. Mettler M, Grimm F, Capelli G, Camp H, Deplazes PJ. Evaluation of enzyme-linked immunosorbent assays, an immunofluorescentantibody test, and two rapid tests (immunochromatographic- 
dipstick and gel tests) for serological diagnosis of symptomatic and asymptomatic Leishmania infections in dogs. Clin Microbiol 2005; 43:5515-5519.

9. Paz GF, Ribeiro MF, Magalhães DF, Sathler KP, Morais MH, Fiúza VO, et al. Association between the prevalence of infestation by Rhipicephalus sanguineus and Ctenocephalides felis felis and the presence of anti-Leishmania antibodies: A case-control study in dogs from a Brazilian endemic area. Prev Vet Med 2010; 97 : 131-133.

10. Costa JO. Ehrlichia canis infection in a dog in Belo HorizonteBrazil. Arq Bras Vet Zootec 1973; 25:199-200.

11. Bastos CV, Moreira SM, Passos LM. Retrospective study (1998-2001) on canine babesiosis in Belo Horizonte, Minas Gerais, Brazil. Ann N Y Acad Sci 2004; 1026:158-160.

12. Aguiar DM, Hagiwara MK, Labruna MB. In vitro isolation and molecular characterization of an Ehrlichia canis strain from São Paulo, Brazil. Braz J Microbiol 2008; 39:489-493.

13. Krawczak FS, Labruna MB, Sangioni LA, Vogel FSF, Soares JF, Lopes STA. Serological survey on Ehrlichia sp. among dogs in the central region of Rio Grande do Sul. Rev Bras Parasitol Vet 2012; 21:415-417.

14. Waner T, Harrus S, Jongejan F, Bark H, Keysary A, Cornelissen AW. Significance of serological testing for ehrlichial diseases in dogs with special emphasis on the diagnosis of canine monocytic ehrlichiosis caused by Ehrlichia canis. Vet Parasitol 2001; 95:1-15.

15. Bicalho KA, Ribeiro MF, Martins-Filho OA. Molecular fluorescent approach to assessing intraerythrocytic hemaprotozoan Babesia canis infection in dogs. Vet Parasitol 2004; 125:221-235.

16. Instituto Interamericano de Cooperación para la Agricultura (Iica). Técnicas para el diagnóstico de babesiosis y anaplasmosis bovina: San José: Iica; 1987.

17. Harrus S, Waner T. Diagnosis of canine monocytotropic ehrlichiosis (Ehrlichia canis): an overview. Vet J 2011; 187: 292-296.

18. Solano-Gallego L, Baneth G. Canine leishmaniosis-a challenging zoonosis. Eur J Comp Anim Pract 2008; 18:232-241.

19. Solano-Gallego L, Koutinas A, Miró G, Cardoso L, Pennisi MG, Ferrer L, et al. Directions for the diagnosis, clinical staging, treatment and prevention of canine leishmaniosis. Vet Parasitol 2009; 165:1-18.

20. Romero GA, Boelaert M. Control of visceral leishmaniasis in latin America - a systematic review. PLoS Negl Trop Dis 2010; 4:e584.

21. Grimaldi Jr G, Teva A, Ferreira AL, dos Santos CB, Pinto IS, de-Azevedo CT, et al. Evaluation of a novel chromatographic immunoassay based on Dual-Path Platform technology (DPP ${ }^{\circ}$ CVL rapid test) for the serodiagnosis of canine visceral leishmaniasis. Trans R Soc Trop Med Hyg 2012; 106:54-59.

22. Solano-Gallego L, Koutinas A, Miró G, Cardoso L, Pennisi MG, Ferrer L, et al. Directions for the diagnosis, clinical staging, treatment and prevention of canine leishmaniosis. Vet Parasitol 2009; 165:1-18.

23. Gomes APS, Cordeiro RLR. Reação cruzada no diagnóstico sorológico de leishmaniose canina. Rev Bras Parasitol Vet 2004; $23: 235-238$

24. Dell' Porto A, Oliveira MR, Miguel O. Babesia canis in stray dogs from the city of São Paulo: Comparative studies between the clinical and hematological aspects and the indirect fluorescence antibody test. Rev Bras Parasitol Vet 1993; 2:37-40.

25. Bartsch RC, Greene RTJ. Post-therapy antibody titers in dogs with ehrlichiosis: follow-up study on 68 patients treated primarily with tetracycline and/or doxycycline. Vet Intern Med 1996; 10:271-274.

26. Otranto D, Dantas-Torres F, Breitschwerdt EB. Managing canine vector-borne diseases of zoonotic concern: part two. Trends Parasitol 2009; 25:228-235.

27. Oliveira TMFS, Furuta PI, Carvalho D, Machado RZ. Study of cross-reactivity in serum samples from dogs positive for Leishmania sp., Babesia canis and Ehrlichia canis in enzymelinked immunosorbent assay and indirect fluorescent antibody test. Rev Bras Parasitol Vet 2008; 17:7-11.

28. Dumler JS, Barbet AF, Bekker CP, Dasch GA, Palmer GH, Ray SC, et al. Reorganization of genera in the families Rickettsiaceae and Anaplasmataceae in the order Rickettsiales: unification of some species of Ehrlichia with Anaplasma, Cowdria with Ehrlichia and Ehrlichia with Neorickettsia, descriptions of six new species combinations and designation of Ehrlichia equi and HGE agent as subjective synonyms of Ehrlichia phagocytophila. Int J Syst Evol Microbiol 2001; 51:2145-2165.

29. Almosny NRP, Massard CL, Labarthe NV, O'dwyer LH, Souza AMDE, Alves LC, et al. Erliquiose em pequenos animais domésticos e como zoonose. In: Almosny NRR, Massard CL, editors. Hemoparasitoses em pequenos animais domésticos e como zoonoses. Rio de Janeiro: LF Livros; 2002; p. 13-56.

30. Ross R. Note on the bodies recently described by LeishmanDonovan and (2) Further notes on Leishman's bodies. British Medical J 1903; 2:1261-1401.

31. Zanette MF, Lima VF, Laurenti MD, Rossi CN, Vides JP, Vieira RFC, et al. Serological cross-reactivity of Trypanosoma cruzi, Ehrlichia canis, Toxoplasma gondii, Neospora caninum and Babesia canis to Leishmania infantum chagasi tests in dogs. Rev Soc Bras Med Trop 2014; 47:105-107. 